\title{
Psychological factors that affect the acceptance and need for ICT services for older adults with chronic diseases
}

\author{
Heui Sug Jo MD PhD MPH ${ }^{\mathrm{a}}$, Yu Seong Hwang $\mathrm{MA}^{\mathrm{a}, *}$ \\ ${ }^{a}$ Department of Health Policy and Management, School of Medicine, Kangwon National \\ University, Republic of Korea ; *Corresponding author: hys1077@kangwon.ac.kr
}

\begin{abstract}
Background: To encourage older adults with chronic disease to use information and communications technology (ICT) services effectively, it is necessary to identify users' needs and factors affecting acceptance.

Objective: To identify the psychological factors affecting the acceptance of ICT services, and the service-related preferences/priorities in home-dwelling South Korean older adults. Method: We conducted focus group interviews with 2 groups of older adults 6 males and 6 females, age $=65-75$ years) with chronic diseases in June 2019. To identify which services they prioritized, we made 20 service show cards, scored on a 5-point Likert scale. Additionally, we utilized a self-developed semi-structured interview guide based on the unified theory of acceptance and use of technology 3 model (UTAUT3) to comprehensively identify how the factors affect older adults' acceptance.

Results: Most participants prioritized their autonomy and worried about being dependent on ICT services. They were also reluctant to learn about and use new technology; feared the social stigma related to "being old"; and were anxious that the use of ICT services could result in deepened isolation. There was ambivalence regarding the impact of ICT services on connection with family/acquaintances. The prioritized services were emergency assistance (e.g., notifying family in case of emergencies), diet and exercise-related information, and medication reminders. Service needs and psychological factors affecting the acceptance differed by gender.

Conclusion: The ICT services offered to the elderly should be developed in a way that guarantees autonomy and supports self-reliance. Services must also ensure the enhancement of social networks and maintenance of connectedness with family. Older people have a fear of learning new services; so, personal guidance and tailored education need to be offered. Further, service development must reflect the diverse needs of each user.
\end{abstract}

Keywords: ICT, healthcare, acceptance, older adults, unified theory of acceptance and use of technology 3 (UTAUT3) model

\section{INTRODUCTION}

The worldwide prevalence of chronic diseases in older adults is on the rise (Stuckler \& Siegel, 2011). In South Korea, the prevalence rate of chronic diseases among older adults amounts to $89.2 \%$; of this, $46.2 \%$ have 3 or more chronic diseases (Oh, 2015). In coping with chronic diseases, lifestyle medicine is essential (Rippe, 2019). Additionally, older adults tend to prefer home-based care services (Miskelly, 2001; Rocha et al., 2013). However, due to the high levels of caregiving burden and the expenses involved, alternative care services are necessary (Kang et al., 2010).

Information and communications technology (ICT) can serve as an alternative because it enables the provision of services tailored to the needs of older adults (Evchina \& Lastra, 2016). Following the breakout of COVID-19, ICT services functioned as home-based healthcare and medical service platforms for monitoring, surveillance, detection, and prevention (Portnoy et al., 2020; Goodman-Casanova, 2020; Ting et al., 2020).

A growing number of studies demonstrate the use of ICT services among older adults. In these studies, ICT services for older adults have been focused mainly on supporting security (Maresova et al., 2020), safety (Miskelly, 2001), comfortable environments (Evchina \& Lastra, 2016; Kashif et al., 2016), and psychological support (Chen \& Schulz, 2016; Jo et al., 2019). Further, studies incorporating ICT into the management of chronic diseases have demonstrated the effects of mHealth technology on cardiovascular disease and diabetes management (Changizi \& Kaveh, 2017), telecare technology on timely interventions (Gokalp et al., 2018), remote virtual sign monitoring on reducing the rate of re-entry and the number of days of hospitalization (Celler 
Table 1. Participant demographics.

\begin{tabular}{lcccc}
\hline Participant \# & Age & Gender & Living alone & Chronic disease \\
\hline 1 & 66 & Male & No & Hypertension, Diabetes \\
2 & 71 & Male & No & Backache, Angina pectoris \\
3 & 65 & Male & No & Diabetes \\
4 & 67 & Male & No & Hypertension, Diabetes, Backache \\
5 & 65 & Male & No & Hypertension \\
6 & 73 & Male & No & Angina pectoris \\
7 & 66 & Female & No & Hypertension, Backache \\
8 & 73 & Female & No & Hypertension, Backache \\
9 & 75 & Female & No & Backache \\
10 & 66 & Female & No & Hypertension \\
11 & 70 & Female & Yes & Hypertension, Diabetes, Arthritis \\
12 & 67 & Female & No & Arthritis \\
\hline
\end{tabular}

baby boomers who have recently retired (or their spouses have retired), and are undergoing life course changes.

To identify the psychological factors affecting the acceptance of ICT services, we need a systematic approach based on a theory. The unified theory of acceptance and use of technology (UTAUT3) model (Farooq

et al., 2003), and ICT on patient empowerment to continue their health activities (Wildevuur \& Simonse, 2015; Alluhaidan et al., 2018). On the other hand, ICT services are problematic in that older adults have low digital literacy (Hasan \& Linger, 2016), have difficulty in using technological devices (dos Santos et al., 2016), and are not familiar with the service contents (Heart \& Kalderon, 2013). Therefore, older adults are likely to either be reluctant to adopt ICT services or outright reject them (Steele et al., 2009).

Several studies have been conducted on factors affecting older adults' acceptance of ICT services. The results indicate that user experience (Hasan \& Linger, 2016; Hur, 2016; Reis et al., 2016), selfefficacy (Hasan \& Linger, 2016; Reis et al., 2016), attitude (Reis et al., 2016), self-determination (Hur, 2016), self-esteem, productivity, pleasure (Hasan \& Linger, 2016), and social bonds (Reis et al., 2016) have positive effects on the acceptance of ICT services.

However, to develop ICT services for chronic disease management that can be accepted and continuously used by older adults requires multilateral and practical investigation. This is evidenced by the fact that many older adults are indifferent to or dislike using new technologies (Kim, 2013), and might fail to specify unmet needs that could be satisfied through services made available by modern technology (Hornung et al., 2017). Additionally, older adults' sociocultural background could influence the psychological factors affecting their acceptance of ICT services (Niehaves \& Plattfaut, 2014) Their experiences of life could also vary depending on gender, with men undergoing post-retirement physical deterioration and psychological atrophy (Hwang et al., 2018). Therefore, this study aimed to identify the factors affecting the acceptance of ICT services as well as the service-related priorities and preferences in older adults aged 65 to 75 years living in South Korea. Identifying these factors is important as people who are currently in this age bracket belong to the generation of et al., 2017) has been widely adopted to describe the acceptance of technology by older adults (Chen \& Chan, 2014; Vassli \& Farshchian, 2018). The UTAUT3 includes factors such as hedonic motivation, price value, and personal innovativeness, which have been added to the former model. Thus, we utilized the UTAUT3 model to comprehensively identify how these factors affect older adults' acceptance of ICT services.

Accordingly, this study addressed the following questions:

(1) How do older adults currently manage chronic diseases, which chronic disease management ICT services reflect potential or unmet needs, and what are the priorities in terms of services?

(2) How do the psychological factors reflected by the users' socio-cultural background (e.g., retirement, gender role, etc.) affect the acceptance of ICT services?

(3) What is the overall attitude of older adults toward ICT services and how can their attitudes be improved?

\section{Methods \\ Data sources}

For this study, we utilized focus group interviews (FGIs), which is "a qualitative research method that is based around a one-off group discussion on a specific topic" (Hopkins, 2016). To this end, we recruited 2 groups ( 6 males and 6 females) of older adults. The inclusion criteria were hospitalization for chronic diseases within the previous 3 years, aged 65-75 years, and living alone or with a spouse. Participants were recruited through a research company named $P \& S$ Jungsung $R e-$ search Co. Ltd.

Table 1 presents the demographic characteristics of the 12 participants. Participants' average age (standard deviation) was 68.6 (3.60) years. The average age of males was 67.7 (3.44) years and that of females was 69.5 (3.83); 11 participants lived with their spouses. FGls were conducted by distinguishing gender, which reduced the burden of elderly people feeling awkward, and 


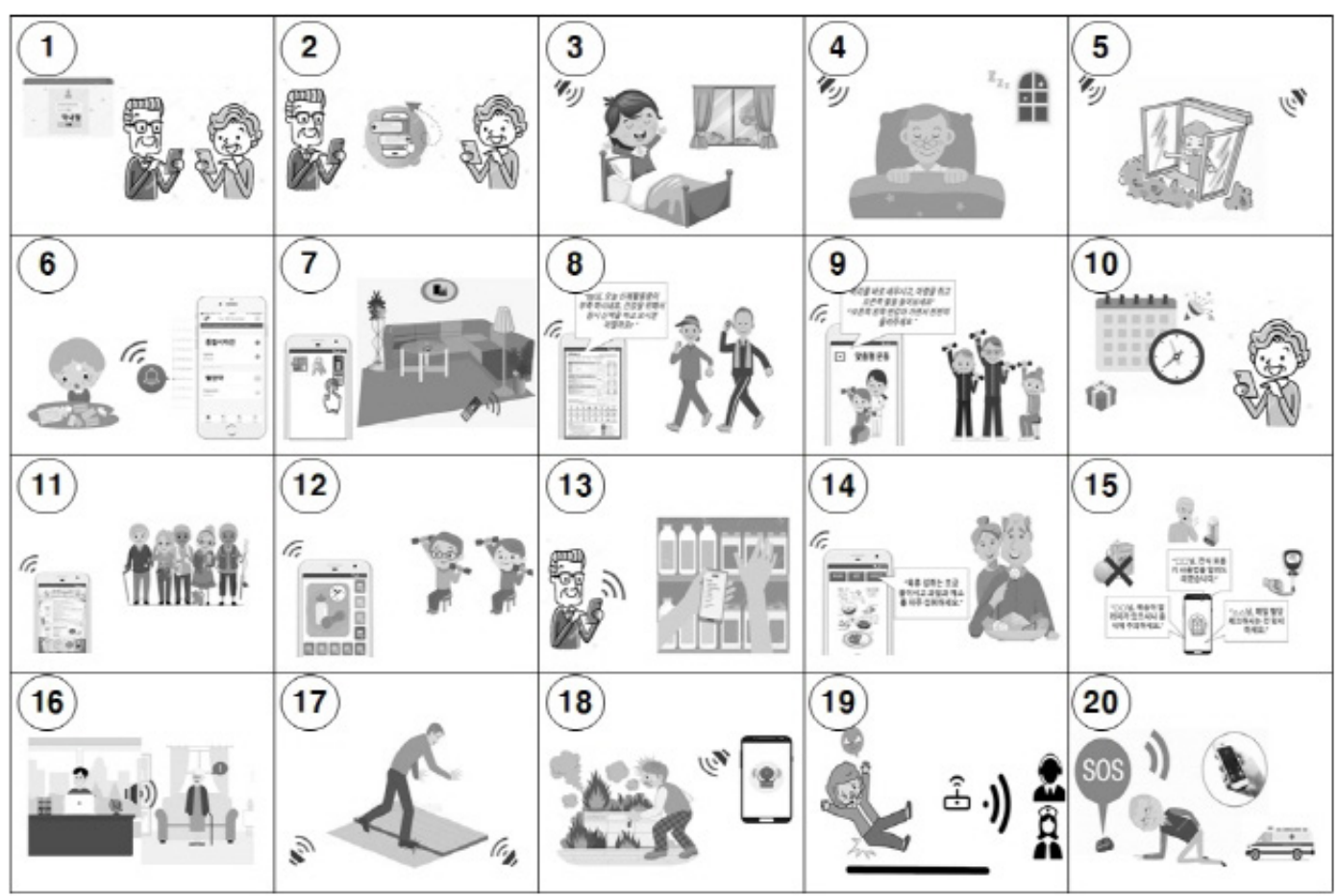

Figure 1. The 20 show cards representing services to assess participants' priorities.

strengthened the formation of consensus to encourage more in-depth conversations.

The concerned institutional review board approved this study (KWNUIRB-2019-05-006-005). Written informed consent was obtained from the participants before the commencement of data collection. Each focus group interview lasted approximately 2 hours. Video and voice recordings were conducted simultaneously in the room assigned for the interview. We assured the participants that the collected data would be anonymized and that they could withdraw at any time without being judged.

\section{Procedure and data analysis}

We conducted a 3-step qualitative data analysis using the transcribed recordings. First, we examined the daily life and self-healthcare of older adults. The main questions asked were: (1) How is your ordinary life? (2) What do you do for your health?

Second, we examined the necessity and selfsufficiency of 20 high-valued ICT services for aging well (Christophorou et al., 2016; Figure 1), and measured them using 5-point Likert scales ranging from "Not at all necessary" to "Fully necessary" and from "Not at all sufficient" to "Fully sufficient", respectively. Explanations for each service given in Figure 1 were presented

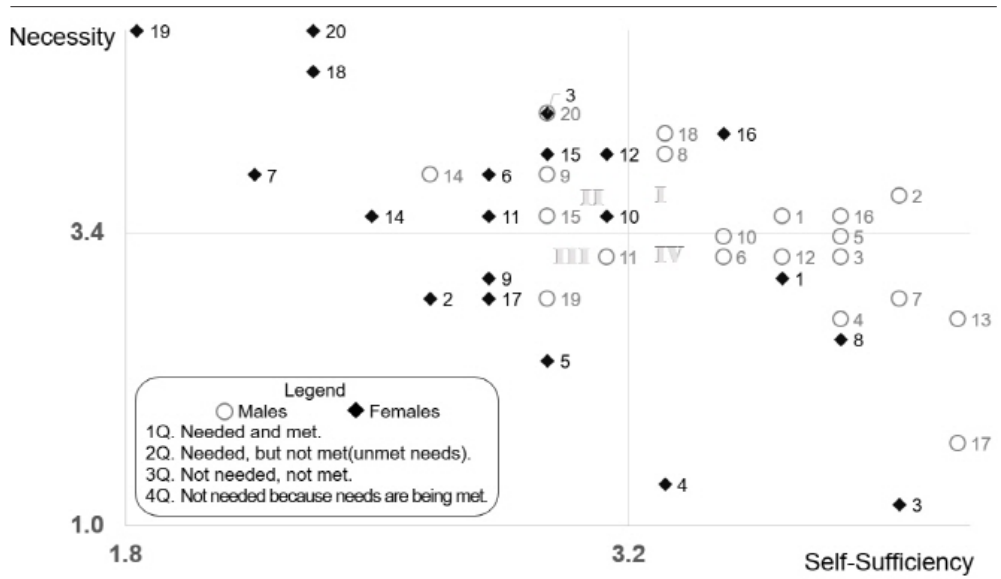
to the participants. The list of services comprised the following: (1) Contact Assistance, (2) Messaging, (3) Wake-up Alarm, (4) Go-to-Bed Reminder, (5) Window Monitoring, (6) Medication Services and Reminders, (7) Object Location Assistance and Reminder, (8) Motivation for Physical Activity, (9) Physical Activity Guide Services, (10) Agenda Services, (11) Event/Group Activities, (12) Appointment Reminders, (13) Shopping, (14) Di-

Figure 2. Quadrant plot for the 20 services by gender. 
Table 2. Semi-structured interview questions based on the unified theory of acceptance and use of technology (UTAUT3) model.

\begin{tabular}{|c|c|}
\hline Theme & Questions \\
\hline Performance expectancy & $\begin{array}{l}\text { What do you expect from an ICT healthcare device for self-care? } \\
\text { Which function do you think is the most useful? }\end{array}$ \\
\hline Effort expectancy & $\begin{array}{l}\text { What are the difficulties you face while using ICT healthcare devices? } \\
\text { Ideally, what should be made easier by using ICT healthcare devices? }\end{array}$ \\
\hline Social influence & $\begin{array}{l}\text { How much are you influenced by your acquaintances regarding ICT healthcare } \\
\text { device usage? } \\
\text { What do the people around you think about your use of ICT healthcare devices? }\end{array}$ \\
\hline $\begin{array}{l}\text { Barriers and facilitating } \\
\text { factors }\end{array}$ & $\begin{array}{l}\text { What are your concerns regarding the use of ICT healthcare devices? } \\
\text { What could make you use such a device to a greater extent? }\end{array}$ \\
\hline Hedonic motivation & $\begin{array}{l}\text { How would you describe the pleasure you feel when using ICT healthcare } \\
\text { devices? }\end{array}$ \\
\hline Cost & What is your expectation of cost regarding the use of ICT healthcare devices? \\
\hline Personal innovativeness & $\begin{array}{l}\text { Are you usually interested in using new devices such as smartphones? } \\
\text { What do you think about learning how to use smart devices? }\end{array}$ \\
\hline
\end{tabular}

etary Assistance, (15) Periodic Advice, (16) Notifications, (17) Dangerous Objects Adviser, (18) Dangerous Situations Adviser, (19) Fall Detection and Alerting, and (20) Call for Help and Alerting. The collected data were placed on a quadrant chart (Figure 2), centered on necessity (y-axis) and self-sufficiency (x-axis), by calculating the average value of each service by gender.

Third, to identify the psychological factors affecting the acceptance of ICT services, we asked questions regarding the older adults' usual perceptions using semi-structured interview questions based on the UTAUT3 model. We implemented the 6 stages of thematic analysis suggested by Braun and Clarke (2006) to categorize themes and concepts. Two authors read the entire transcripts three times to become familiar with the data, generated initial codes, organized them into separate themes and concepts using the UTAUT3 model (Faroog et al., 2017), and reached a consensus regarding opinions on the themes and concepts. Questions related to the following 7 themes presented in the UTAUT 3 model were utilized: performance expectancy, effort expectancy, social influence, barriers and facilitating factors, hedonic motivation, cost, and personal innovativeness (Table 2).

\section{Results}

\section{Daily life and self-care management}

Males: vacantness and despondency; females: usualness and connectedness

The results showed that male participants experienced boredom and vacantness after retirement and that they felt frustrated and despondent in their newfound routine.

"There's nothing to do every day ... I am becoming very lazy..." (Interviewee \#2)

"I don't know what to do." (Interviewee \#5)
"I don't have anything special to do, so sometimes I feel suffocated in daily life." (Interviewee \#6)

Contrastingly, female participants expressed that their everyday lives proceeded as usual, and reported engaging in various group activities.

"I wake up at 4:00 a.m. ... I get back home from church around 6:30 a.m., and eat breakfast by 7:00 a.m...." (Interviewee \#7)

"I do line dance class on Mondays and Wednesdays, Korean dance class on Tuesdays and Thursdays, and on days I don't go anywhere, I hang out with my friends." (Interviewee \#10)

\section{The insecurity of home treatment}

Both male and female participants reported being insecure about home treatment. They reported that, after discharge from the hospital, they did not care about lifestyle management; their only concern was taking their medication. Nonetheless, medication adherence was not high, and they had concerns about the side effects of drugs since they had to take large amounts and various kinds of medicine.

Further, although they were aware of the importance of diet and weight control in daily life, they said it was difficult to practice control.

"Sometimes I forget to take my medicine, so, after a year of treatment, I still have a month's worth of medication left." (Interviewee \#2)

"I took a lot of medicine, so much so that I didn't even know there were aspirins or 2 thrombotic drugs..." (Interviewee \#2)

"... 7 tablets in the morning, but the medicine could have several side effects, so I try to take less medicine ..." (Interviewee \#3)

"I was told I should not eat salty dishes... But that didn't work." (Interviewee \#6) 
Moreover, they were dependent on the medical staff for disease management but reported that they could not receive sufficient consultation.

"There are so many patients ... I can't say anything because he (the doctor) is just looking at the computer." (Interviewee \#3)

"I take medicine as much as the physician gives me, and if the physician advices me to take an examination, I just take it." (Interviewee \#8)

\section{Necessity and self-sufficiency regarding ICT services}

We examined the necessity and self-sufficiency of ICT services among the 20 high-valued ICT services for aging well proposed by Christophorou and colleagues (2016). We calculated each services' average of necessity and self-sufficiency and presented in a plotted graph. The average of necessity was 3.37, and that of selfsufficiency was 3.23. We used the averages as borderline values and separated (plotted) 20 services in(to) 4 quadrants by gender (Figure 2). Services in the first quadrant (I) had both higher than average necessity and self-sufficiency which are considered as needed, and the older adults currently use them sufficiently. The second quadrant (II) includes services with higher necessity and lower self-sufficiency compared to the average; these services are considered as unmet needs. The services in the third quadrant (III) had necessity and self-sufficiency lower than average, and they are reported as neither needed nor sufficient. Finally, services in the fourth quadrant (IV) includes services with lower necessity and higher self-sufficiency compared to the average, and they are considered as not needed but sufficient services.

Female participants denoted more service items in the second quadrant (II) compared to males, implying that women tend to have more unmet needs. For both male and female participants, services regarding emergency assistance as (18) Dangerous Situations Adviser and (20) Call for Help and Alerting were demonstrated as needed but insufficient. Additionally, males demonstrated a need for lifestyle management services, such as (14) Dietary Assistance, and (9) Physical Activity Services. The female participants demonstrated a need for self-management services, such as (6) Medication Service and Reminders; and assistance services, such as (7) Object Location Assistance and Reminder and (12) Appointment Reminders.

In terms of Daily Life and Self-Care Management, the elderly showed an insecure attitude toward home treatment. Nevertheless, here we found that they desire to manage their life if they can.

\section{Themes and concepts in ICT-based services}

Participants were also asked about the psychological factors influencing their use of ICT-based healthcare services. In this subsection, the data are organized by the themes of the UTAUT3 model.

\section{Performance expectancy}

Autonomy

In response to our question, the older adults denied the necessity of any ICT services. However, we discovered that they are afraid of losing their autonomy by using these services. Generally, participants considered independence and autonomy as important values; that is, rather than relying on ICT-based services, they wanted to do what they could on their own. Additionally, they wished for ICT services to help them become more autonomous.

"I don't need them (ICT services) at all." (Interviewee \#2)

"I don't need help regarding anything I do." (Interviewee \#4)

"Older people don't want them (ICT services). Young people might want to be more comfortable." (Interviewee \#6)

"Since I have a lot of family members, I wish it (an ICT service) would check their birthdays and let me know." (Interviewee \#7)

\section{Notification}

The participants also replied that they needed service to alert their families in case of illness/ emergency.

"I think it's most important that the device automatically detects and informs my family if I collapse and do not wake up after a while." (Interviewee \#3)

"If you fall when you're alone, nobody knows. It would be great if it could automatically inform the hospital or 119 (emergency service) ..." (Interviewee \#2)

\section{Health-related behaviors}

The participants responded that they needed services that would help them support their healthrelated behaviors.

"When I go to the gym, there are instructors, but I can't repeatedly question them unless I pay for them ... I wish it (ICT services) could provide me with the right tips for what I need ..." (Interviewee \#2)

"(I want) ICT services which alert me to exercise in the morning, alert me time to take medicines, give me proper dietary suggestion, like, 'You would be better off cutting back on eating meat."' (Interviewee \#4) 


\section{Effort expectancy}

Learning new technology

Respondents reported that they had difficulty in learning new ICTs.

"It's hard to learn (how to use new devices)." (Interviewee \#10)

"I think it (using new ICT) is stressful until I get used to it." (Interviewee \#11)

\section{Continuous use concerns}

Participants were concerned about the continuous use of the ICT services in case they did not operate normally (e.g., errors or malfunctioning).

"If it breaks down, it's hard to repair and troublesome to call someone." (Interviewee \#8)

\section{Social influence}

Free will

Participants demonstrated that it is not common to use ICT services on the recommendation of the people around them. Rather, their preferences for using specific services and their priorities were more important than the social recommendations they received.

"(To begin using ICT-based services/devices), we need to have felt inconvenienced in some way first. We must need it (ICT service). It shouldn't be forced." (Interviewee \#5)

\section{Concern about others' opinions}

Although recommendation from others regarding their need to accept ICT services was not important, participants reported caring about others' perceptions and opinions about what they used in their daily lives. The older adults tended to think that relying on ICT for healthcare proves that they are old.

"When I use this, I feel old. I hate this because I'm afraid my children may feel I am getting too old." (Interviewee \#11)

\section{Facilitating and barrier factors}

Being watched is not a big deal

Among our sample, rather than worrying about privacy (i.e., being hesitant to use services that may deliver their personal information to companies and people they do not know), participants reported wanting to feel like they were being watched and that they were connected to others.

"If my children keep a watch and monitor this (a camera-related ICT service), I don't care, I'd rather be more thoroughly monitored." (Interviewee \#5)

Reducing interactions with people

Meanwhile, they were also concerned that the frequency of visits and telephone calls from their children would be reduced if their children could monitor their health status through ICT services.

"I'm worried that if I use this, I won't be able to get in touch with my children. Because, (if I asked) 'Why don't you come over to my house one of these days?' they would say, 'Dad, we don't have to. You're all right. I know everything about you through the device.' They might reach such conclusions ... I'm afraid that the device could allow for them to neglect calling or visiting me frequently." (Interviewee \#3)

There exists ambivalence in the desire for being watched (facilitating factor) and concern about reduced interaction with people (barrier factors).

\section{Hedonic motivations}

Cure for boredom and facilitating connections The older adults hoped to use ICT services for leisure, for instance, as a source of information and entertainment and to watch the news or videos, such as movies, dramas, or footages. Additionally, they hoped to use the services to assist them in communicating with family members and to acquire useful information regarding daily living (food, shopping, popup events, etc.).

"There's nothing to do at home. I don't have anything to do other than browsing the Internet or using the cellphone." (Interviewee \#1)

"I wish I could have more contact with my family through this." (Interviewee \#6)

"When I searched for better recipes, I could find lots of good information." (Interviewee \#9)

\section{Cost}

Affordability of products

The participants, who have no economic income owing to being retired, were very sensitive to the pricing of products and provided overall negative responses to products with high prices.

"Twenty different types of ICT services would be nice. Nonetheless, it's an economic matter." (Interviewee \#5)

"I don't need anything expensive." (Interviewee \#11)

"I don't understand why I should pay a few hundred thousand won for each (of these services). Why would I buy a feature that I can't use anyway?" (Interviewee \#8)

\section{Personal innovativeness}

\section{Familiarity with smartphones}

There were individual variations in participants' usage of ICT services. Generally speaking, it was found that mobile phones (smartphones) are mostly utilized for what can be considered a "usual" use.

"A smartphone is an intimate thing. Without it, I feel incomplete and perpetually curious about 


\begin{tabular}{|c|c|}
\hline $\begin{array}{l}\text { Performance Expectancy } \\
\text { "Autonomy, independence" } \\
\text { "I want my family notified in case of an emergency." } \\
\text { "I need an explanation how to eat healthy and exercise." }\end{array}$ & \\
\hline $\begin{array}{l}\text { Effort Expectancy } \\
\text { "I'm afraid of using new devices." } \\
\text { "I'm afraid there will be frequent breakdowns." }\end{array}$ & \\
\hline "I'll use it if I want to." & \\
\hline $\begin{array}{l}\text { Barrier-Facilitating Factors } \\
\text { "It's not a big deal to be watched." }\end{array}$ & $\begin{array}{c}\text { Use Intention } \\
\text { for } \\
\text { ICT Healthcare } \\
\text { Devices }\end{array}$ \\
\hline $\begin{array}{l}\text { Hedonic Motivations } \\
\text { "I want to use it for entertainment and to stay connected with } \\
\text { those around me." }\end{array}$ & \\
\hline "I can't buy it if it's expensive." & \\
\hline $\begin{array}{l}\text { Personal Innovativeness } \\
\text { "I'm used to using smartphones." }\end{array}$ & \\
\hline
\end{tabular}

Figure 3. Factors related to acceptance of ICT healthcare devices. life, the necessity of and selfsufficiency regarding healthcare ICT services, and acceptance of ICT-based healthcare devices. So far, solutions for increasing ICT service acceptance have been focused mainly on developing topnotch technologies (de Belen et al., 2019). However, as provider-oriented technologies, they have struggled to be accepted. Therefore, we applied a person-centered care approach that examines individuals' problems and needs in a narrative way (Wildevuur \& Simonse, 2015).

The participants of this study were relatively younger South Korean older adults (aged 65-75), who had prior experience of using the latest smart
eping in mind our very specific who might have been attempting to contact me." (Interviewee \#8)

"I feel uneasy and worried if I don't carry my phone. It's like I have left something important behind." (Interviewee \#12)

"It (cellphone) has to be by my side at home as well." (Interviewee \#10)

\section{Individual variance in usage and experience} Although the respondents were using a mobile phone, there was considerable variance in utilization level. For example, many of them used online banking services, but some of them didn't use them due to security concerns. Moreover, individual experience also has a significant impact on personal innovativeness. For example, a participant who had an experience of using a tablet PC had favorable views on the device and service.

(Some participants replied with "No" to the question "Do you use online banking?"), "I don't use online banking because I think there might be a security problem." (Interviewee \#2)

(Some participants said "Yes" in reply to the question "Have you ever used a tablet PC?") "I loved it. My daughter said, 'Mom, you can watch YouTube with this.'" (Interviewee \#10)

Figure 3 depicts a schematic diagram of themes and concepts related to the participants' acceptance of ICT healthcare devices.

\section{Discussion}

To investigate the psychological factors affecting home-dwelling older adults' acceptance of ICTbased healthcare services through qualitative analyses, we interviewed them about their daily devices. Thus, keeping in mind our very specific
sample, we believe our study offers important implications for the future development of ICTbased healthcare devices and services that may come to better reflect the values and preferences of these end-users. Overall, the attitude of older adults toward ICT can be summed up as "seems necessary but I am still hesitant"; in other words, they feel they need help in daily life and healthcare management, even though they don't want any intervention or change in lifestyle.

Three psychological factors that older adults feel like "seem necessary" were found, and we suggested strategies to encourage each of the necessity aspects.

First, the older adults in our study want to be motivated and live actively and autonomously through ICT-based healthcare services. A previous study corroborated our findings that older adults seem to want healthcare devices that 2018). In the interview about their daily life and self-care management, older adults displayed an often forgot to take their medication on time. Additionally, despite their awareness regarding the importance of exercise and a healthy diet, their rates of implementing these behaviors were low.

Nevertheless, they want to empower their passive lifestyle by managing it more actively through ICT services. A number of studies have found this tendency (Wildevuur \& Simonse, 2015, Alluhaidan et al., 2018). Typically, females displayed a tendency to require services on which they ensure their independence (Vassli \& Farshchian, insecure attitude toward home treatment. They 
could be dependent (e.g., alarms, object location tracking and medication reminders), whereas males seemed to desire services that could aid them to live actively and autonomously (e.g., physical activity services providing tips/lessons, meal preparation assistance). Prioritized services were varied based on individual lifestyle, socioeconomic status, physical and mental functioning, preferences, and characteristics (Ghasemi et al., 2017.) Therefore, various services satisfying older adults' individual requirements need to be developed (Lee, 2018). In addition, as a common necessity for health management, services improving medication adherence are strongly recommended. Apart from the results, efforts will be needed to develop services that provide geriatric support (e.g. vision-, hearing-, kinesthetic-, and cognitive decline-related support) for older adults to live independently and autonomously (Fischer et al., 2014).

Second, the older adults in this study felt they need services to help in emergency situations. Participants reported that they would like for the ICT-based healthcare devices to perform safety functions, such as notifying their family members/acquaintances in the event of an emergency (e.g., sudden health deterioration, falling, or fire) they cannot manage by themselves. In a previous study from which we extracted the 20 proposed services, older adults and their caregivers also rated safety-related functions as essential (Christophorou et al., 2016). Therefore, developing emergency notifications is strongly recommended.

Third, prior technology experience can increase older adults' likelihood of adopting new technologies (Lazaro, Lim, Kim, \& Yun, 2020). The participants claimed that they prefer using ICT technology for leisure, such as seeking information, playing games, and shopping (Ivankina et al., 2017). In addition, they were using ICT services for communication with family and acquaintances. Therefore, it is possible to incorporate health care services into ICT services already used by older adults. For example, guiding them on how to exercise during leisure time, giving them information on healthy diets and shopping for healthy ingredients, and informing them of their health status through mobile apps. This will encourage older adults to make good use of ICT-based healthcare and feel like active users (Hoenig et al., 2003).

We also identified psychological factors related to "being hesitant" and suggested new solutions for the related aspects.

First, they regarded learning new things as a nuisance. The interviewees in this study showed fear of using new services. They felt uneasy about using the new device because they have had an experience of having difficulty learning how to operate new technology, needing someone to help them, and worrying about breaking it. Moreover, even though the development of electronic devices has led to the creation of many new functions, they tend to only use those that they are familiar with. It is corroborated by previous researches (Castilla et al., 2018; Kapadia et al., 2015), and this can lead to a strong rejection of these newer devices (Pal et al., 2018). Therefore, ICT-based healthcare devices should be designed to be simple and easy to operate. It is also recommended that an easy-to-understand manual containing large pictures and simple descriptions be provided, and service centers where older adults can get help easily be set up (Vassli \& Farshchian, 2018).

Additionally, fear may have a negative impact on use intention and acceptance because it reduces the impact of the positive aspects of the utility of ICT-based services/devices. It has been shown that the lower the digital literacy, the higher the fear regarding technology use (Lee \& Huang, 2014). A preliminary study also discovered that older adults with regular ICT training are more likely to use ICT services (Hasan \& Linger, 2016). Therefore, to give older adults the necessary training on use and maintenance, educational programs teaching service utilization should be developed at the same time as ICT services (Xie, 2012; Zhao et al., 2020).

Second, they had anxiety about their families relying too much on ICT services and consequently, reducing contact or visits. Prior researches have also pointed out that using ICT services may potentially replace human interactions and make older adults feel lonelier (Abolhassani et al., 2019). In this context, studies have also found that older adults feel isolation anxiety (Kirmizioglu et al., 2009), loneliness (Holmén \& Furukawa, 2002), and boredom (Bantwal, 2016) in their daily lives. Therefore, ICT services should be designed to facilitate connections with family and acquaintances. While ICT healthcare devices had been developed for monitoring and assistance of older adults so far (Rosado, Abásolo, \& Silva, 2019), it is recommended that they now be used as communication tools for older adults and their descendants.

Third, the older adults in our study were also concerned about the possible social stigma that comes with being perceived as "old people" owing to their need to rely on ICT services. A previous study also reported that acceptance toward such services/devices was found to be lowered because of a social stigma (Abolhassani et al., 2019). Therefore, the shape, size, and color of the devices providing ICT services should be suit- 
able for the elderly while also remaining trendy. Furthermore, to relieve social stigma, it is important to proliferate the social atmosphere with ICT healthcare devices. Such cultural change would require the support of government policy tools, such as pilot projects, promotion programs, and cost assistance.

\section{Conclusion}

The development of ICT services related to medication reminders and emergency notifications must be prioritized in the context of home-dwelling older adults with chronic diseases. It should be strongly considered to include autonomy empower services, motivating services, and provision of real-time feedback. Additionally, emotional support may be needed to help them communicate with their families, which may help reduce boredom and loneliness. Meanwhile, since older adults have a high degree of fear and reluctance regarding the use of digital devices, ICT services must be easy to operate, and older adults must receive the required training to facilitate familiarization. Further, accounting for gender differences and preferences during product and service development is necessary. Finally, policymakers and stakeholders must make greater efforts to promote social acceptance of the care of older adults through ICT services.

\section{Limitations}

As this is a qualitative study, the sample size was small, limiting the representation of South Korean home-dwelling older adults. Further, the present results cannot be generalized to all South Korean older adults because the participants were relatively younger older adults.

\section{Acknowledgements}

This research was supported by Basic Science Research Program through the National Research Foundation of Korea(NRF) funded by the Ministry of Science and ICT(No. NRF-2019R1A2C1005840).

\section{References}

Abolhassani, N., Santos-Eggimann, B., Chiolero, A., Santschi, V., \& Henchoz, Y. (2019). Readiness to accept health information and communication technologies: A population-based survey of community-dwelling older adults. International Journal of Medical Informatics, 130, 103950. https://doi. org/10.1016/j.ijmedinf.2019.08.010

Alluhaidan, A., Chatterjee, S., Drew, D., \& Stibe, A. (2018, April). Sustaining health behaviors through empowerment: a deductive theoretical model of behavior change based on information and communication technology (ICT). In International Conference on Persuasive Technology (pp. 28-41). Springer, Cham. https://doi.org/10.1007/978-3-319-78978-1_3

Bantwal, P. (2016). Existence of boredom among the elderly: The need to further explore the concept. Journal of Geriatric Care and Research, 3(2), 49-50.

Braun, V., \& Clarke, V. (2006). Using thematic analysis in psychology. Qualitative Research in Psychology, 3(2), 77-101. https://doi. org/10.1191/1478088706qp063oa.

Castilla, D., Botella, C., Miralles, I., Bretón-López, J., Dragomir-Davis, A. M., Zaragoza, I., \& GarciaPalacios, A. (2018). Teaching digital literacy skills to the elderly using a social network with linear navigation: A case study in a rural area. International Journal of Human-Computer Studies, 118, 24-37. https://doi.org/10.1016/j.ijhcs.2018.05.009

Celler, B. G., Lovell, N. H., \& Basilakis, J. (2003). Using information technology to improve the management of chronic disease. Medical Journal of Australia, 179(5), 242-246. https://doi. org/10.5694/j.1326-5377.2003.tb05529.x

Changizi, M., \& Kaveh, M. H. (2017). Effectiveness of the mHealth technology in improvement of healthy

behaviors in an elderly population-a systematic review. Mhealth, 3. https://doi.org/10.21037/ mhealth.2017.08.06

Chen, K., \& Chan, A. H. S. (2014). Gerontechnology acceptance by elderly Hong Kong Chinese: a senior technology acceptance model (STAM). Ergonomics, 57(5), 635-652. https://doi.org/10.1080/001401 39.2014.895855

Chen, Y. R., \& Schulz, P. J. (2016). The effect of information communication technology interventions on reducing social isolation in the elderly: A systematic review. Journal of Medical Internet Research, 18(1), e18. https://doi.org/10.2196/jmir.4596

Christophorou, C., Kleanthous, S., Georgiadis, D., Cereghetti, D. M., Andreou, P., Wings, C., Christodoulou, E., \& Samaras, G. (2016). ICT services for active ageing and independent living: Identification and assessment. Healthcare Technology Letters, 3(3), 159-164. https://doi.org/10.1049/ htl.2016.0031

de Belen, R. A. J., Del Favero, D., \& Bednarz, T. (2019, July). Combining Mixed Reality and Internet of Things: An Interaction Design Research on Developing Assistive Technologies for Elderly People. In International Conference on Human-Computer Interaction (pp. 291-304). Springer, Cham. https://doi. org/10.1007/978-3-030-22015-0_23

dos Santos, M. M. T., Antonelli, H. L., Rodrigues, S. S., Silva, C. L. O., Fortes, R. P. M., \& Castro, P. C. (2016, December). Personalizing health-related ICT interface and application: Older adults and elderly caregivers' preferences [Paper presentation]. 7th International Conference on Software Development and Technologies for Enhancing Accessibility and Fighting Info-exclusion: DSAI 2016, Vila Real, Portugal. https://doi.org/10.1145/3019943.3019991

Evchina, Y., \& Lastra, J. L. M. (2016). An ICT-driven hybrid automation system for elderly care support: A rehabilitation facility study case. Journal of Housing for the Elderly, 30(1), 52-74. https://doi.org/10.1 080/02763893.2015.1129382

Farooq, M. S., Salam, M., Jaafar, N., Fayolle, A., Ayupp, 
K., Radovic-Markovic, M., \& Sajid, A. (2017). Acceptance and use of lecture capture system (LCS) in executive business studies. Interactive Technology and Smart Education, 14(4), 329-348. https:// doi.org/10.1108/ITSE-06-2016-0015

Fischer, B. L., Gleason, C. E., Gangnon, R. E., Janczewski, J., Shea, T., \& Mahoney, J. E. (2014). Declining cognition and falls: role of risky performance of everyday mobility activities. Physical therapy, 94(3), 355-362. https://doi.org/10.2522/ptj.20130195

Ghasemi, S., Mohammadi, N. K., Shahboulaghi, F. M., \& Ramezankhani, A. (2017). A critical review of studies on health needs assessment of elderly in the world. Elderly Health Journal, 3(1), 1-9. Retrieved from http://ehj.ssu.ac.ir/article-1-73-en.html

Gokalp, H., de Folter, J., Verma, V., Fursse, J., Jones, R., \& Clarke, M. (2018). Integrated telehealth and telecare for monitoring frail elderly with chronic disease. Telemedicine and e-Health, 24(12), 940-957. https://doi.org/10.1089/tmj.2017.0322

Goodman-Casanova, J. M., Dura-Perez, E., GuzmanParra, J., Cuesta-Vargas, A., \& Mayoral-Cleries, F. (2020). Telehealth home support during COVID-19 confinement for community-dwelling older adults with mild cognitive impairment or mild dementia: survey study. Journal of Medical Internet Research, 22(5), e19434. https://doi.org/10.2196/19434

Hasan, H., \& Linger, H. (2016). Enhancing the wellbeing of the elderly: Social use of digital technologies in aged care. Educational Gerontology, 42(11), 749-757. https://doi.org/10.1080/03601277.2016.1205425

Heart, T., \& Kalderon, E. (2013). Older adults: Are they ready to adopt health-related ICT? International Journal of Medical Informatics, 82(11), e209-e231. https://doi.org/10.1016/j.ijmedinf.2011.03.002

Hoenig, H., Taylor, D. H., Jr., \& Sloan, F. A. (2003). Does assistive technology substitute for personal assistance among the disabled elderly? American Journal of Public Health, 93(2), 330-337. https://doi. org/10.2105/ajph.93.2.330

Holmén, K., \& Furukawa, H. (2002). Loneliness, health and social network among elderly people-a follow-up study. Archives of Gerontology and Geriatrics, 35(3), 261-274. https://doi.org/10.1016/S01674943(02)00049-3

Hopkins, P. (2016). Focus groups. In International Encyclopedia of Geography: People, the Earth, Environment and Technology (pp. 1-4). John Wiley \& Sons. https:// doi.org/10.1002/9781118786352.wbieg0150

Hornung, D, Müller, C., Shklovski, I., Jakobi, T., \& Wulf, V. (2017, May). Navigating relationships and boundaries: Concerns around ICT-uptake for elderly people [Paper presentation]. 2017 Conference on Human Factors in Computing Systems: CHI, Denver, CO. https://doi.org/10.1145/3025453.3025859

Hur, M. (2016). Empowering the elderly population through ICT-based activities: An empirical study of older adults in Korea. Information Technology \& People, 29(2), 318-333. https://doi.org/10.1108/ ITP-03-2015-0052

Hwang, M. Y., Chung, S. D., \& Kim, J. H., (2018) The Relationship Among Ageism, Self-Perception of Physiological \& Psycho-social Aging, and Depressive Mood: Comparison between Male Babyboom- er, Young-Old \& Old-Old Generation Groups. The Korean Psychological Association, 37(1), 65-103. https://doi.org/10.22257/kjp.2018.03.37.1.65

Ivankina, L. I., Trubchenkob, T. G., Krukovacc, E. M. Shaidullinad, A. R., Shaftelskayae, N. V., \& Chernyak, V. K. (2016, September). The use of information and communication technologies by elderly people [Paper presentation]. III International Scientific Symposium on Lifelong Wellbeing in the World: WELLSO 2016, Tomsk, Russian Federation. https://doi.org/10.15405/epsbs.2017.01.32

Jo, H. S, Kim, J. H., \& Kim, S. (2019). Factors related to the effectiveness in the use of an ICT-based toy robot for the in-home care of community dwelling elderly. Korean Journal of Health Education and Promotion, 36(5), 43-51. https://doi.org/10.14367/ kjhep.2019.36.5.43

Kang, H. G., Mahoney, D. F., Hoenig, H., Hirth, V. A., Bonato, P., Hajjar, I., \& Lipsitz, L. A. (2010). In situ monitoring of health in older adults: Technologies and issues. Journal of the American Geriatrics Society, 58(8), 1579-1586. https://doi.org/10.1111/ j.1532-5415.2010.02959.x

Kapadia, V., Ariani, A., Li, J., \& Ray, P. K. (2015). Emerging ICT implementation issues in aged care. International journal of medical informatics, 84(11), 892-900. https://doi.org/10.1016/j.ijmedinf.2015.07.002

Kashif, N., Ibrahim, A. A. A., Wu, L., Adamov, A., \& Deen, J. M. (2016, October). Smart home for elderly living using Wireless Sensor Networks and an Android application [Paper presentation]. 2016 IEEE 10th International Conference on Application of Information and Communication Technologies: AICT, Baku, Azerbaijan. https://doi.org/10.1109/ ICAICT.2016.7991655

Kim, K. O. (2013). The emotional responses of older adults to new technology (Doctoral dissertation, University of Illinois at Urbana-Champaign). Available at: https://www.ideals.illinois.edu/handle/2142/42369 [Searched in 2020. 8. 17]

Kirmizioglu, Y., Doğan, O., Kuğu, N., \& Akyüz, G. (2009). Prevalence of anxiety disorders among elderly people. International Journal of Geriatric Psychiatry, 24(9), 1026-1033. https://doi.org/10.1002/gps.2215

Lazaro, M. J. S., Lim, J., Kim, S. H., \& Yun, M. H. (2020). Wearable technologies: acceptance model for smartwatch adoption among older adults. In Q. Gao, \& J. Zhao (Eds.) Human aspects of IT for the aged population. Technologies, design and user experience. HCII 2020. Lecture notes in computer science (vol 12207, pp. 303-315). Springer, Cham. https://doi.org/10.1007/978-3-030-50252-2_23

Lee, C. L., \& Huang, M. K. (2014). The influence of computer literacy and computer anxiety on computer self-efficacy: The moderating effect of gender. Cyberpsychology, Behavior, and Social Networking, 17(3), 172-180. https://doi.org/10.1089/ cyber.2012.0029.

Lee, J. A. (2018). Trends and challenges of using welfare technology in elderly care. International Journal of Contents, 14(2), 30-34.

Maresova, P., Krejcar, O., Barakovic, S., Husic, J. B., Lameski, P., Zdravevski, E., ... \& Trajkovik, V. 
(2020). Health-Related ICT Solutions of Smart Environments for Elderly-Systematic Review. IEEE Access, 8, 54574-54600. https://doi.org/10.1109/ ACCESS.2020.2981315

Miskelly, F. G. (2001). Assistive technology in elderly care. Age and Ageing, 30(6), 455-458. https://doi. org/10.1093/ageing/30.6.455

Niehaves, B., \& Plattfaut, R. (2014). Internet adoption by the elderly: Employing IS technology acceptance theories for understanding the age-related digital divide. European Journal of Information Systems, 23, 708-726. https://doi.org/10.1057/ejis.2013.19

Oh, Y. H. (2015). The health status of older Koreans and policy considerations. Health and Welfare Policy Forum, 2015, 223, 29-39. Available at: http://repository.kihasa.re.kr/handle/201002/14931 (searched in 2020. 8. 17)

Pal, D., Funilkil, S., Charoenkitkarn, N., \& Kanthamanon, P. (2018). Internet-of-things and smart homes for elderly healthcare: An end user perspective. IEEE Access, 6, 10483-10496. https://doi.org/10.1109/ ACCESS.2018.2808472

Portnoy, J., Waller, M., \& Elliott, T. (2020). Telemedicine in the Era of COVID-19. The Journal of Allergy and Clinical Immunology: In Practice, 8(5), 1489-1491. https://doi.org/10.1016/j.jaip.2020.03.008

Reis, A., Parede, H., Barroso, I., Monteiro, J. M., Rodrigues, V., Khanal, S. R., \& Barroso, J. et al. Autonomous systems to support social activity of elderly people a prospective approach to a system design [Paper presentation]. 2016 1st International Conference on Technology and Innovation in Sports, Health and Wellbeing: TISHW, Vila Real, Portugal. https://doi.org/10.1109/TISHW.2016.7847773

Rippe, J. M. (Ed.). (2019). Lifestyle medicine. CRC Press.

Rocha, A., Martins, A., Freire, J. C. Jr., Boulos, M. N. K., Escriche Vicente, M. E., Feld, R., van de Ven, P., Nelson, J., Bourke, A., OLaighin, G., Sdogati, C., Jobes, A., Narvaiza, L., \& Rodríguez-Molinero, A. (2013). Innovations in health care services: The CAALYX system. International Journal of Medical Informatics, 82(11), e307-e320. https://doi. org/10.1016/j.ijmedinf.2011.03.003

Rosado, M., Abásolo, M. J., \& Silva, T. (2019). ICT ori- ented to the elderly and their active aging: A systematic review. In M. Abásolo, R. Kulesza, J. Pina Amargós (Eds) Applications and usability of interactive TV. jAUTI 2019. Communications in computer and information science (vol 1202, pp. 134-155). Springer, Cham. https://doi.org/10.1007/978-3030-56574-9_9

Steele, R., Lo, A., Secombe, C., \& Wong, Y. K. (2009). Elderly persons' perception and acceptance of using wireless sensor networks to assist healthcare. International Journal of Medical Informatics, 78(12), 788-801. https://doi.org/10.1016/j.ijmedinf.2009.08.001

Stuckler, D., \& Siegel, K. (Eds.). (2011). Sick societies: responding to the global challenge of chronic disease. Oxford University Press.

Ting, D. S. W., Carin, L., Dzau, V., \& Wong, T. Y. (2020). Digital technology and COVID-19. Nature medicine, 26(4), 459-461. https://doi.org/10.1038/ s41591-020-0824-5

Vassli, L. T., \& Farshchian, B. A. (2018). Acceptance of health-related ICT among elderly people living in the community: A systematic review of qualitative evidence. International Journal of Human-Computer Interaction, 34(2), 99-116. https://doi.org/10 $.1080 / 10447318.2017 .1328024$

Wildevuur, S. E., \& Simonse, L. W. (2015). Information and communication technology-enabled personcentered care for the "big five" chronic conditions: scoping review. Journal of medical Internet research, 17(3), e77. https://doi.org/10.2196/jmir.3687

Xie, B. (2012). Improving older adults' e-health literacy through computer training using $\mathrm{NIH}$ online resources. Library \& information science research, 34(1), 63-71. https://doi.org/10.1016/j. lisr.2011.07.006

Zhao, X., Wang, L., Ge, C., Zhen, X., Chen, Z., Wang, J., \& Zhou, Y. (2020). Smartphone application training program improves smartphone usage competency and quality of life among the elderly in an elder university in China: A randomized controlled trial. International journal of medical informatics, 133, 104010. https://doi.org/10.1016/j.ijmedinf.2019.104010 